\title{
Preparation of Hydrophobic Poly (lauryl methacrylate-divinyl benzene) Coated Magnetic Nano-composite Particles and Their Application as Adsorbents for Organic Pollutants
}

\author{
Rukhsana Shabnam* and Hasan Ahmad \\ Department of Chemistry, University of Rajshahi, Rajshahi 6205, Bangladesh. \\ *Corresponding author: samarhass@yahoo.com
}

\begin{abstract}
This work introduces a method for the preparation of magnetic nano-composite particles coated with highly crosslinked poly (lauryl methacrylate) (PLMA), a hydrophobic polymer containing long chain alkyl groups for application in waste water treatment. The produced magnetic composite particles named $\mathrm{Fe}_{3} \mathrm{O}_{4} / \mathrm{SiO}_{2} / \mathrm{P}(\mathrm{LMA}-\mathrm{DVB})$ were characterized by Fourier Transform IR (FTIR), Transmission electron microscopy (TEM) and X-ray diffractometer (XRD) analyses. Then the prepared composite particles were used for the removal of organic pollutants from water. The adsorption behavior was dependent on the nature of the pollutants with congo red showed highest adsorption efficiency.
\end{abstract}

Keywords: Lauryl methacrylate (LMA); Suspension polymerization; Hydrophobic; Nano-composite; Organic pollutant.

\section{INTRODUCTION}

In the modern era, a chemist or an industrialist is going with a great challenge to face the contamination of the underground sources in irreversible way with recalcitrant and nonbiodegradable organics [1-5]. Organic compounds have many industrial applications such as pesticides, synthetic rubber, plastic, pharmaceuticals, petrochemicals, textiles, leather and in other industries $[6,7]$. Therefore organic pollutants can be widely found in various industrial wastewaters. Most of these are considered as toxic, carcinogenic, mutagenic and teratogenic and thus considered dangerous chemical substances because they can accumulate in the human body and initiate a wide variety of symptoms such as headache, cough, nausea and shock [8]. Due to the improved dispersibility in water/salt and compatibility with the organic pollutant, the polymer-coated magnetic nanoparticles offer advantages on removal of pollutants. Resins for chromatographic separation, water purification, oil absorbency agents, viscosity modifiers, oil-soluble drag reducers etc. are the well-known applications of hydrophobic latex particles [9, 10]. The coating of hydrophobic polymer on $\mathrm{Fe}_{3} \mathrm{O}_{4}$ particles is expected to increase adsorption ability, particularly of organic pollutant.

LMA is a well-known industrially important hydrophobic monomer because it has long chain alkyl group, which in addition to its hydrophobicity also gives polymers with high flexibility (low glass transition temperature, $T_{g}$ ). In this investigation we prepared highly cross-linked PLMA coated magnetic nano-composite particles by restricting the polymerization of LMA and divinylbenzene (DVB) within the droplets containing $\mathrm{Fe}_{3} \mathrm{O}_{4} / \mathrm{SiO}_{2}$ particles using oil-soluble initiator. The morphology, size distribution and application potential of $\mathrm{Fe}_{3} \mathrm{O}_{4} / \mathrm{SiO}_{2} / \mathrm{P}(\mathrm{LMA}-\mathrm{DVB})$ composite particles as adsorbent for organic pollutants have been examined. 


\section{EXPERIMENTAL}

\section{A. Chemicals and instruments}

LMA from Fluka, Chemika (Switzerland) was washed with $10 \% \mathrm{NaOH}$ aqueous solution to remove any inhibitor and finally passed through activated basic alumina by column chromatography. Crosslinking agent DVB from Sigma-Aldrich, Chemie ( $80 \%$ grade) was purified with aqueous $10 \% \mathrm{NaOH}$ solution and subsequently dehydrated by stirring with anhydrous $\mathrm{CaCl}_{2}$. Benzoyl peroxide (BPO) from BDH Chemicals Ltd., UK was recrystallized from methanol and preserved in the refrigerator before use. Tetraethylorthosilicate (TEOS) from Sigma Aldrich, USA, was preserved in the refrigerator and used without purification. Other chemicals were of analytical grade. Deionized water was distilled using a glass (Pyrex) distillation apparatus.

Transmission electron microscope (TEM) was performed with a JSEM-1230 microscope (JEOL, Tokyo, Japan) operating at a voltage of $100 \mathrm{kV}$, and optical image was obtained by a fluorescence microscope (IX71 Olympus, Japan) to see the particle morphology and size distribution. FTIR (Perkin Elmer, FTIR-100, USA), X-ray diffractometer (Bruker D8 Advance, Germany) were used for the characterization of the latex particles.

\section{B. Preparation of $\mathrm{Fe}_{3} \mathrm{O}_{4} / \mathrm{SiO}_{2} / \mathrm{P}(\mathrm{LMA}-\mathrm{DVB})$ particle}

Magnetic $\left(\mathrm{Fe}_{3} \mathrm{O}_{4}\right)$ nano particles were prepared by co-precipitation of $\mathrm{Fe}^{2+}$ and $\mathrm{Fe}^{3+}$ from their alkaline aqueous solutions as reported elsewhere [11]. $\mathrm{Fe}_{3} \mathrm{O}_{4}$ nanoparticles were encapsulated with $\mathrm{SiO}_{2}$ using TEOS. Then precipitation copolymerization was carried out using LMA and DVB in presence of $\mathrm{Fe}_{3} \mathrm{O}_{4} / \mathrm{SiO}_{2}$ particles within stable droplets containing hexadecane-toluene mixture (4:1 mixture HD-T) as porogen using BPO (2\% $\mathrm{w} / \mathrm{w}$ based on monomer) as an initiator. The produced magnetic composite particles named $\mathrm{Fe}_{3} \mathrm{O}_{4} / \mathrm{SiO}_{2} / \mathrm{P}(\mathrm{LMA}-\mathrm{DVB})$ were washed by repeated replacement of continuous phase with distilled water.

\section{Adsorption behavior of organic pollutants on $\mathrm{Fe}_{3} \mathrm{O}_{4} / \mathrm{SiO}_{2} / \mathrm{P}(\mathrm{LMA}-\mathrm{DVB})$ particle}

For adsorption measurement, purified $\mathrm{Fe}_{3} \mathrm{O}_{4} / \mathrm{SiO}_{2} / \mathrm{P}(\mathrm{LMA}-\mathrm{DVB})$ composite particles were mixed with aqueous solution of Gramaxone, Phenol, Salicylic acid and Congo red respectively. Allowing the dispersion-pollutant mixture to stand for $2 \mathrm{~h}$ and then the amount of adsorption was measured using UV-visible spectrophotometer.

\section{RESULTS AND DISCUSSION}

TEM images of $\mathrm{Fe}_{3} \mathrm{O}_{4} / \mathrm{SiO}_{2}$ and $\mathrm{Fe}_{3} \mathrm{O}_{4} / \mathrm{SiO}_{2} / \mathrm{P}(\mathrm{LMA}-\mathrm{DVB})$ composite particles are shown in Figure 1. The average diameters are $43 \mathrm{~nm}$ and $52.6 \mathrm{~nm}$ for $\mathrm{Fe}_{3} \mathrm{O}_{4} / \mathrm{SiO}_{2}$ and $\mathrm{Fe}_{3} \mathrm{O}_{4} / \mathrm{SiO}_{2} / \mathrm{P}(\mathrm{LMA}-\mathrm{DVB})$ composite particles. The small increase is attributed to the coverage of $\mathrm{Fe}_{3} \mathrm{O}_{4} / \mathrm{SiO}_{2}$ particles with cross-linked PLMA layer. Due to nano dimension it is not possible to confirm the core-shell structure. The composite particles are bit coagulated while drying during sample preparation.

The analysis of FTIR spectra polymer particles is well known for the determination of surface composition. For $\mathrm{Fe}_{3} \mathrm{O}_{4} / \mathrm{SiO}_{2}$ nanoparticles, the strong bands at $543 \mathrm{~cm}^{-1}$ and 376 $\mathrm{cm}^{-1}$ are due to $\mathrm{Fe}-\mathrm{O}$ stretching vibrations of the magnetic nanoparticles. The strong band at $1059 \mathrm{~cm}^{-1}$ that corresponds to $\mathrm{Si}-\mathrm{O}-\mathrm{Si}$ bonds indicates the bonding of $\mathrm{SiO}_{2}$ to $\mathrm{Fe}_{3} \mathrm{O}_{4}$. The appearance of the signals at 3400 and $1617 \mathrm{~cm}^{-1}$ changed a bit from those of $\mathrm{Fe}_{3} \mathrm{O}_{4}$ particles and can be explained by taking into account the stretching and bending vibrations of $\mathrm{Si}-\mathrm{O}-\mathrm{H}$. Compared to this the intense bands due to $\mathrm{Si}-\mathrm{O}-\mathrm{Si}$ and 
$\mathrm{Fe}-\mathrm{O}$ bonds in $\mathrm{Fe}_{3} \mathrm{O}_{4} / \mathrm{SiO}_{2}$ particles weakened or almost disappeared in $\mathrm{Fe}_{3} \mathrm{O}_{4} / \mathrm{SiO}_{2} / \mathrm{P}(\mathrm{LMA}-\mathrm{DVB})$ composite particles. The new peaks that appear in the region 2761-2968 $\mathrm{cm}^{-1}$ represent aliphatic - $\mathrm{CH}$ stretching vibrations of aliphatic chain. The small signal at $1710 \mathrm{~cm}^{-1}$ corresponds to the stretching vibration of ester carbonyl group derived from LMA. The shoulder peak at around $3000 \mathrm{~cm}^{-1}$ may correspond to the aromatic $-\mathrm{CH}$ stretching vibration of DVB crosslinker. These results confirmed the formation of trilayered magnetic $\mathrm{Fe}_{3} \mathrm{O}_{4} / \mathrm{SiO}_{2} / \mathrm{P}(\mathrm{LMA}-\mathrm{DVB})$ composite particles.
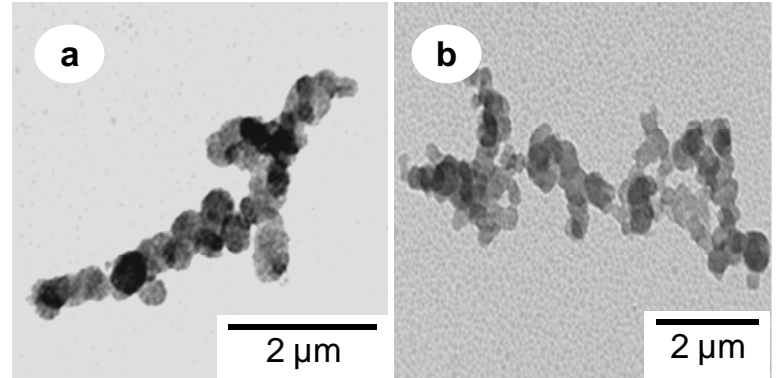

Fig. 1. TEM images of a) $\mathrm{Fe}_{3} \mathrm{O}_{4} / \mathrm{SiO}_{2}$ and b) $\mathrm{Fe}_{3} \mathrm{O}_{4} / \mathrm{SiO}_{2} / \mathrm{P}(\mathrm{LMA}-\mathrm{DVB})$ composite particles.

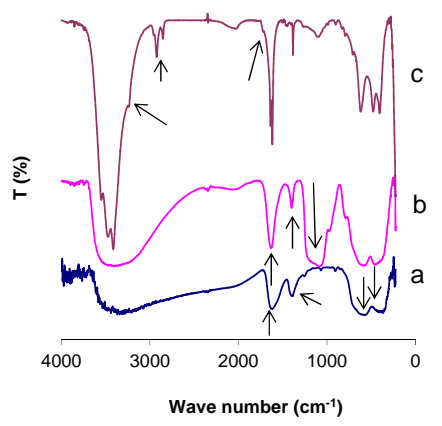

Fig. 2. FTIR spectra of a) $\mathrm{Fe}_{3} \mathrm{O}_{4}$, b) $\mathrm{Fe}_{3} \mathrm{O}_{4} / \mathrm{SiO}_{2}$ and c) $\mathrm{Fe}_{3} \mathrm{O}_{4} / \mathrm{SiO}_{2} / \mathrm{P}(\mathrm{LMA}-\mathrm{DVB})$ composite particles recorded in $\mathrm{KBr}$ pellets.

XRD pattern of polymer modified $\mathrm{Fe}_{3} \mathrm{O}_{4} / \mathrm{SiO}_{2}$ composite particles shown in Figure 3 exhibits six characteristic peaks for $\mathrm{Fe}_{3} \mathrm{O}_{4}$ nanoparticles at $30.3^{\circ}, 35.6^{\circ}, 43.5^{\circ}, 54.0^{\circ}$, $57.4^{\circ}$ and $63.0^{\circ}$, which can be assigned to (220), (311), (400), (422), (511) and (440), respectively. These signals matched well with the database of magnetite in the JCPDSInternational Center (Joint Committee on Powder diffraction Standards (JCPDS) Card: 19-0629) [12]. The peak positions remained the same during different steps of modification indicating that the crystalline structure of the magnetite is essentially maintained. The amorphous character of $\mathrm{SiO}_{2}$ and copolymer is represented by the broad diffraction signal averages at $13.2^{\circ}$. 


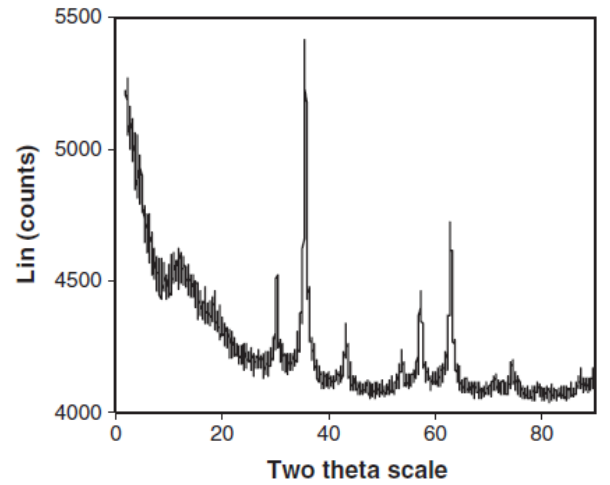

Fig. 3. XRD spectra of $\mathrm{Fe}_{3} \mathrm{O}_{4} / \mathrm{SiO}_{2} / \mathrm{P}(\mathrm{LMA}-\mathrm{DVB})$ composite particles.

The efficiency of $\mathrm{Fe}_{3} \mathrm{O}_{4} / \mathrm{SiO}_{2} / \mathrm{P}(\mathrm{LMA}-\mathrm{DVB})$ composite particles as an adsorbent for organic pollutants is shown in Figure 4. It is likely that adsorption of pollutants on composite particles is driven by the hydrophobic interaction as the composite particles are coated with hydrophobic P(LMA-DVB) layer. It is evident that the magnitude of adsorption is dependent on the nature as well as molecular size of the pollutants. Adsorption efficiency was calculated based on the total amount of pollutant taken in aqueous solution for measuring amount of adsorption. It can be mentioned that the concentration of the respective pollutant was fixed by their solubility limit. The adsorption efficiency reached maximum for hydrophobic large molecular weight Congo red followed by phenol [13]. Composite particles had minimum loading efficiency for herbicide. It is most likely that the higher water solubility of the pollutant is responsible for poor adsorption efficiency.
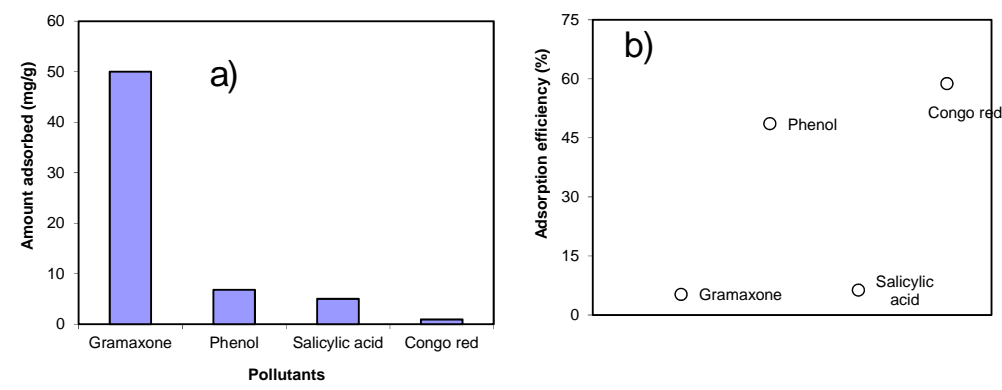

Fig. 4. Adsorption magnitude (a) and adsorption efficiency (b) of pollutants on magnetic $\mathrm{Fe}_{3} \mathrm{O}_{4} / \mathrm{SiO}_{2} / \mathrm{P}(\mathrm{LMA}-\mathrm{DVB})$ composite particles measured at room temperature.

\section{CONCLUSIONS}

Magnetic hydrophobic polymer-coated $\mathrm{Fe}_{3} \mathrm{O}_{4} / \mathrm{SiO}_{2} / \mathrm{P}(\mathrm{LMA}-\mathrm{DVB})$ nano-composite particles were prepared via suspension polymerization in mixed monomer-solvent (hexadecane-toluene) droplets containing $\mathrm{Fe}_{3} \mathrm{O}_{4} / \mathrm{SiO}_{2}$ nanoparticles. The structure of 
composite polymer particles was confirmed by FTIR and XRD analyses. The magnetic composite particles had a nano-dimension in the dried state as observed from the electron micrograph. The removal of different organic pollutants by magnetic composite particles is driven by hydrophobic interaction.

\section{Acknowledgment}

The instrumental support from the Central Science Laboratory, Rajshahi University, is gratefully acknowledged.

\section{References}

[1] Ding Y, Zhao Y, Tao X, Zheng Y-Z, Chen J-F, “Assembled alginate/chitosan microshells for removal of organic pollutants," Polymer, vol. 50, pp. 2841-2846, 2009.

[2] Aloulou F, Boufi S, Labidi J, "Modified cellulose fibres for adsorption of organic compound in aqueous solution,” Sep. Purif. Technol., vol. 52, pp. 332-342, 2006.

[3] Aravindhan R, Rao J-R, Nair B-U, J. "Environmental application of a chemically modified green macro alga as a biosorbent for phenol removal," J. Environ. Manag., vol. 90, pp. 1877-1883, 2009.

[4] Bayramoglu G, Arica M-Y, "Enzymatic removal of phenol and p-chlorophenol in enzyme reactor: Horseradish peroxidase immobilized on magnetic beads," J. Hazard. Mater., vol. 156, pp. 148-155, 2008

[5] Ahmad H, Nurunnabi M, Rahman M-M, Kumar K, Tauer K, Minami H, Gafur M-A, "Magnetically doped multi stimuli-responsive hydrogel microspheres with IPN structure and application in dye removal," Colloids Surf. A: Physicochem. Eng. Aspects, vol. 459, pp. 39-47, 2014.

[6] Zhang S, Zhao X, Niu H, Shi Y, Cai Y, Jiang G, "Superparamagnetic $\mathrm{Fe}_{3} \mathrm{O}_{4}$ nanoparticles as catalysts for the catalytic oxidation of phenolic and aniline compounds," J. Hazard. Mater., vol. 167, pp. 560-566, 2009.

[7] Esquerdo V-M, Cadaval T-R-S Jr., Dotto G-L, Pinto L-A-A, "Chitosan scaffold as an alternative adsorbent for the removal of hazardous food dyes from aqueous solutions," $\mathrm{J}$. Colloid Interface Sci., vol. 424, pp. 7-15, 2014.

[8] Kammona O, Dini E, Kiparissides C, Allabashi R, "Synthesis of polymeric microparticles for water purification," Microporous and Mesoporous Mater., vol. 110, pp. 141149, 2008.

[9] Xu W-J, Zhu X-L, Cheng Z-P, "Atom transfer radical polymerization of lauryl methacrylate,” J. Appl. Polym. Sci., vol. 90, pp. 1117-1125, 2003.

[10] Xu Y-Y, Becker H, Yuan J-Y, Burkhardt M, Zhang Y, Walther A, Bolisetty S, Ballauff M, Muller A-H-E, "Double-grafted cylindrical brushes: synthesis and characterization of poly(lauryl methacrylate) brushes," Macromol. Chem. Phys., vol. 208, pp. 1666-1675, 2007.

[11] Ahmad H, Waesmin M-A, Rahman M-M, Miah M-A-J, Tauer K, "Preparation of Hydrophobic Polymer Particles by Radical Polymerization and Subsequent Modification into Magnetically Doped Particles,” J. Appl. Polym. Sci., vol. 127, pp. 620-627, 2013.

[12] Zheng X, Wang Q, Jiang Y, Gao J, "Biomimetic synthesis of magnetic composite particles for laccase immobilization,” Ind. Eng. Chem., vol. 51, pp. 10140-10146, 2012.

[13] Li Y, Cao R, Wu X, Huang J, Deng S, Lu X, "Hypercrosslinked poly(styrene-codivinylbenzene) resin as a specific polymeric adsorbent for purification of berberine hydrochloride from aqueous solutions," J. Colloid Interface Sci., vol. 400, pp. 78-87, 2013. 